\title{
Evolving Competitive Electricity Markets: Enablement through Advanced Analytics and Cognitive Solutions
}

\author{
Jayaprakash Ponraj ${ }^{* 1}$ and Dr. A. Chandra Mohan ${ }^{2}$ \\ ${ }^{1}$ Research Scholar, Masters in Business Administration, VELS University, \\ Pallavaram, Chennai Pin 600043, India \\ ${ }^{1}$ Senior Managing Consultant, IBM GBS E\&U Center of Competence, India \\ ${ }^{2}$ Professor of Management Studies, SRM University, Chennai, Pin 603203, India.
}

\begin{abstract}
Background/Objectives: This paper will discuss an approach to achieve the autonomous market objective through the effective use advanced analytics and cognitive solutions powered by internet of things and mobility.

Methods/Statistical analysis: Worldwide landscape of electricity industry such as business, grid and asset management alongside customer experience and market models are transforming quite rapidly towards achievement of autonomous electricity markets. Governments, their regulatory bodies and utility organizations are focusing on establishing new business models and thus help stage-manage their people, organization and its governance structure towards achievement of their objectives. The fact that there are enormous differences in the outcome achieved by utilities worldwide is explained through this study of internal and external factors influencing the progress of movement to autonomous state.
\end{abstract}

Findings: This study of global utilities brings out three key internal influences depictions such as people, organization behaviors as well as key technology readiness. In this paper various influences such as shrinking grid businesses due to various challenges such as increasing micro grids or distributed generation resources, regulatory pressures on cost reduction with the ageing infrastructure and diminishing skills are discussed. Specific focus has been given on grid organizations with the emphasis to prevent them from death spiral due to 
shrinking grid businesses. This paper explains why these technologies are imperatives to energy and utility organizations and how they will empower every stakeholder with digital experience and equal opportunity to perform their businesses while in the challenging environment.

Applications/Improvements: This paper does not include discussion around other influences such as people, organization \& social behaviors, traditional applications and solutions that help manage the business as usual. Hence it is proposed to continue the research work to cover the detailed aspects and publish in the further proceedings.

Keywords: electricity markets, cognitive solutions, advanced analytics, technology influences, business model.

\section{INTRODUCTION}

Worldwide landscape of electricity industry ${ }^{1}$ such as business, grid (transmission and distribution power network) and asset management alongside customer experience and market models ${ }^{2}$ are quite rapidly towards achievement of autonomous electricity markets. This study focusses on establishing an approach and requirements to achieve the autonomous market objective through the effective use advanced analytics and cognitive solutions powered by internet of things and mobility and are discussed in the following sections. It also provide perspective of why these technologies are imperatives to the industry organizations in order to tackle their challenges and how they will empower every stakeholders with digital experience and equal opportunity to perform their businesses while in the challenging environment is discussed. Detailed correlation of the study with reference to the target solutions is planned to be included in the future publications. This paper does not include discussion around other influences such as people, legal \& regulatory framework, organization \& social behaviors, prevailing applications, standards and solutions that help manage the business as usual.

\section{STUDY OF MATURITY TOWARDS COMPETITIVE MARKETS}

In order to bring out the focus on approach to realize end objective of establishment of competitive markets and enabling autonomy in the electricity utility segment, worldwide various studies in combination with practices are being evaluated and trialed. This study was focused on publications and reports from various entities such as governments, regulators, utility organizations such as generation including renewables, trading segment and on natural monopolies such as transmission and distribution grids. Competition, the process of challenge between organizations striving to gain sales and make profits, is the driving force behind markets. The Figure 1 represents various steps taken by worldwide utilities to realize end maturity of competitive benefits. 


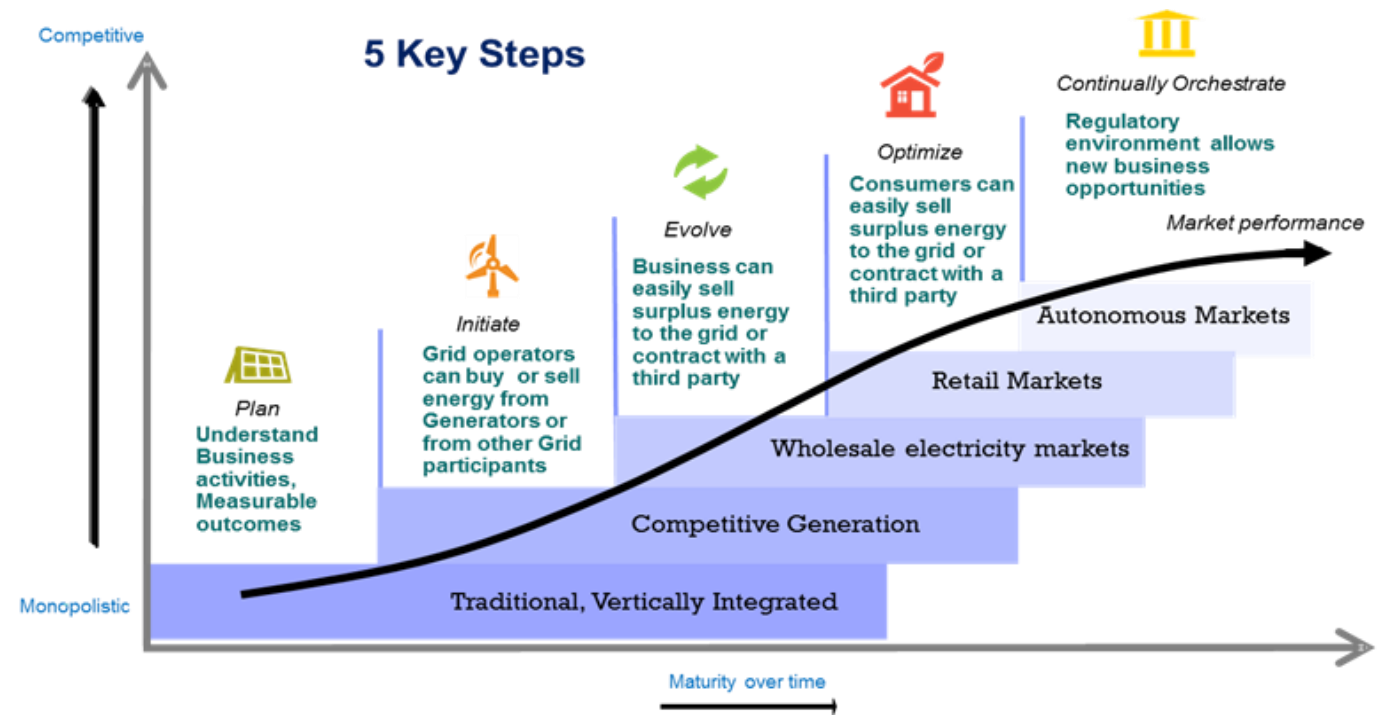

Figure 1: Evolving maturity state of Competitive Electricity Markets

\subsection{Autonomous Markets}

The term autonomous market is used in context of describing maturity level of electricity utility markets. At this state of maturity, regulatory environment would allow stakeholder organizations to define and run new business opportunities or models which are not conceding competitive environment themselves. Most utilities move towards achieving the autonomous state through various initiatives challenging the internal and external influences. One of the key characteristics which would allow existence of this environment is empowerment of every stakeholder organizations with digital experience to perform their role with economy. And it also should ensure allowance of disruptive innovation to be introduced, verified and validated through existing knowledge and information. Stimulating dynamic peripheral system in which a business competes is the key consternation for most countries to promote economic growth \& development. In this environment more stakeholders (sellers of a similar product or service) competes, enjoy economic viability and does not get castigated due to missing data to make informed decisions to perform business.

\subsection{Study of internal and external influences}

Detailed study of global utilities on internal and external influences challenging movement towards autonomous market reveals that utilities have attained divergent level of maturity and experiences on their journey towards achieving autonomous markets. The following are some of key current trends such as unbundling or organizational alignment, exponential inclusion of renewables such as photo voltaic, wind energy in the grid, innovative new business models to include energy storage, increasing regulatory pressures vs ageing infrastructure, diminishing resource skills, reducing oil \& gas prices across the globe, liberalization of import restrictions etc., are 
posing major threat to utilities sustenance influencing the current status of the maturity. Some of the key trends are explained in the below section with some illustrations.

\subsubsection{Rapidly growing micro grids and distributed generation}

The Figure 2 represents falling cost of solar PV generated electricity plotted for about three decades by Citibank in 2013. Renewable generation ${ }^{3}$ such as Solar Photovoltaics (PV), offshore wind plants are conquering exponential momentum generally due to attractive benefits such as declining cost per energy produced, enhanced plant load factors etc., In many countries PV prices have crossed grid parity even from retail customer perspective and thus set to go into competitive market space without any subsidies. However as these distributed generation have intermittency behavior, utilities need to look for satisfying major obstacles to expanding consumption such as ramp events, spinning reserve etc., The variability of distributed generation spots a challenge to those who want to turn them into a profitable alternative energy sources. Hence it is obvious that better forecasting and optimized dispatch can alleviate these barriers. For case in point in India, weighted average bid price for solar PV have been drastically reduced from INR 12.36 per kWh in 2010 to INR 5.36 per kWh now. Market insights including recent revised report from IEA on solar PVs suggests greater reduction in costs about 2 cents per $\mathrm{kWh}$. In many countries solar PV prices have crossed grid parity ${ }^{4}$ even from retail customer perspective and thus set to go into competitive market space without any subsidies. This helps developing nations to declare multifold upsurge of renewable targets. For example recently Indian energy leaders have envisioned target of about 1, 75,000 MW of solar PV capacity growth in 2022. To give an energy scale perspective Indian power grid met peak demand of 1 , 41,180 MW which includes power from grid connected solar PV installed capacity of during the year 2014 .

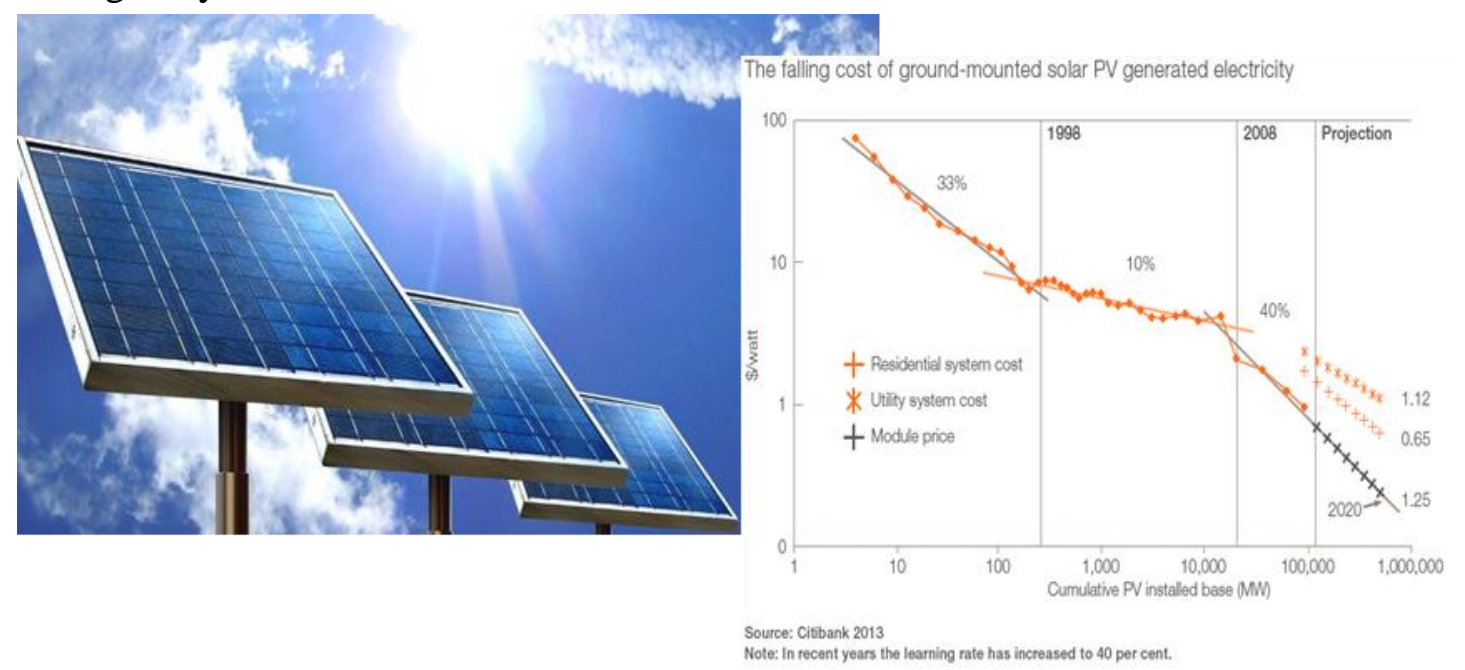

Figure 2: Falling cost of solar PV generated electricity

Other global examples include, E-ON ${ }^{5}$ which is privately-owned energy supplier implementing its new strategy, of focusing entirely on renewables, energy networks 
and customer solutions. The conventional generation, global energy trading and exploration and production businesses segments are being transferred to a new company. E-on's energy networks represent one of the three core businesses of its strategy, already deliver lots of green electricity to customers across Germany. E.ON networks in Germany are home to a total of 32 gigawatts of renewables capacity, about as much as 100 large offshore wind farms.

\subsubsection{Robust advent of energy storage technologies}

Concept of zero energy buildings or organizations were endured, with the robust advent of energy storage technologies and in fact many consumers are looking beyond towards powering the grid thanks to encouragement offered by utilities. In developing countries where challenge for high power network reliability is in existence, typically residential \& commercial consumers depend on batteries as energy storage mechanisms. In fact distributed generation combined with energy storage have been proved more dependable in many countries. However more accurate demand and supply predictions are essential to manage demand vs supply and ensure energy storage business is sustainable. The Figure 3 indicates the cost of batteries are dropping in last decade. For case initiatives by North America utilities (such as SDGE) are encouraging customer owned batteries (BYOB) to encounter other challenges such as peak demand can be reviewed. In Australia Reposit power integrates solar, storage, and controllable loads into a single energy system ${ }^{6}$.

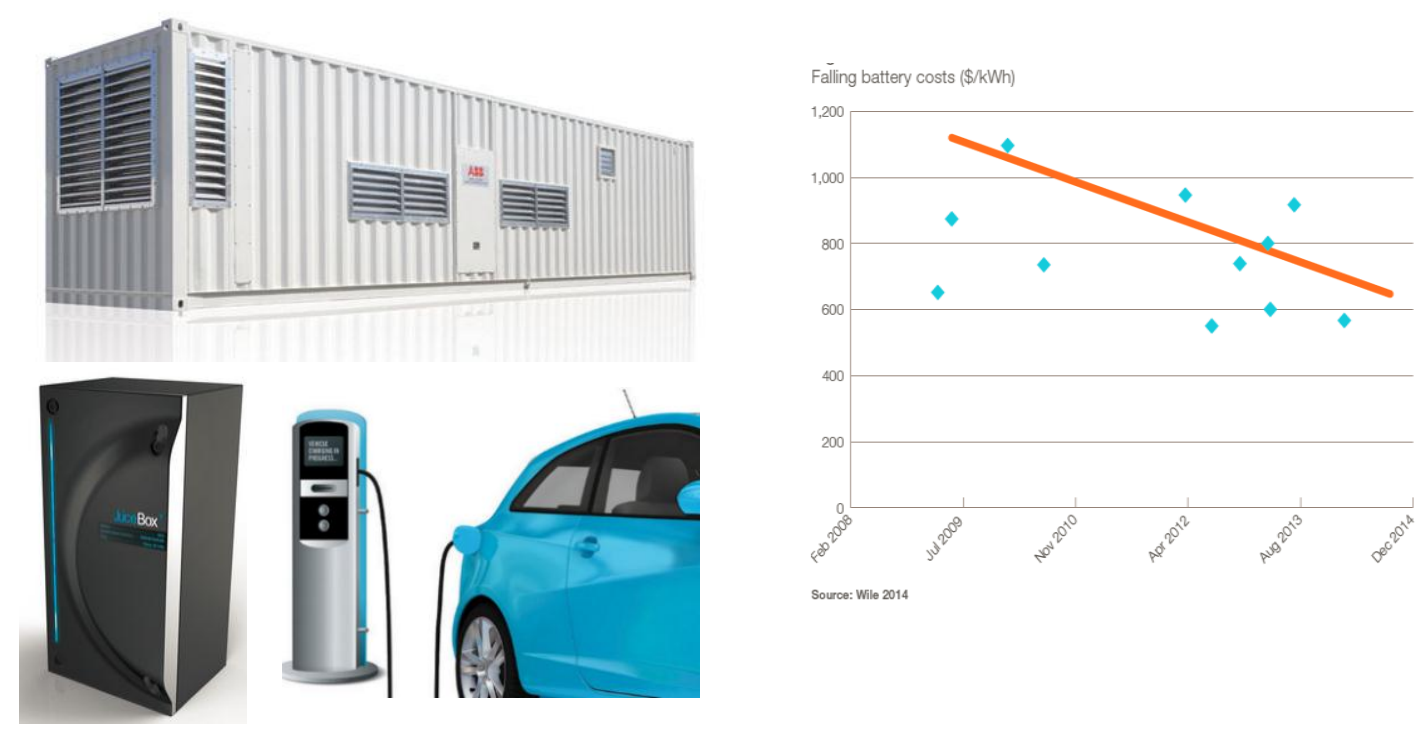

Figure 3: Declining battery costs in $\$ / \mathrm{kWh}$

\subsubsection{Exponential upsurge of data}

Globally utilities have been implementing various solutions in order to manage their business effectively. The Figure 4 sourced from EPRI, GTM research indicates the 
annual rate of data intake in Terabytes would increase exponentially. And this increases further steep when futuristic first of a kind solutions such as autonomous protection (including Wide Area Monitoring Solutions (WAMS) for transmission, Wide Area Control Solutions (WACS) such as setting less protection for distribution) are implemented. Typically Phasor Measurement Units (PMU) are sampled at a rate of 48 samples per second. In such cases considering large number of PMUs on a distribution system to perform use cases like setting less protection, huge exponential data upsurge would occur. And the study validated that many of innovating utilities are already on path of selecting, trailing and implementing appropriate technologies in place to manage the business, grid and assets better. For example, Power Grid Corporation in India trailing on Wide Area Measurement Solutions since 2008. Comparison can be had with reference to the existing level of data rate in many utilities. For example, energy consumption units stored once in two months vs data rate @ 48-144 samples per day to implement advanced demand response solution and manage peak demand. Another key example include data reads from PMU @48 - 96 samples per sec depending the application and latency of features.

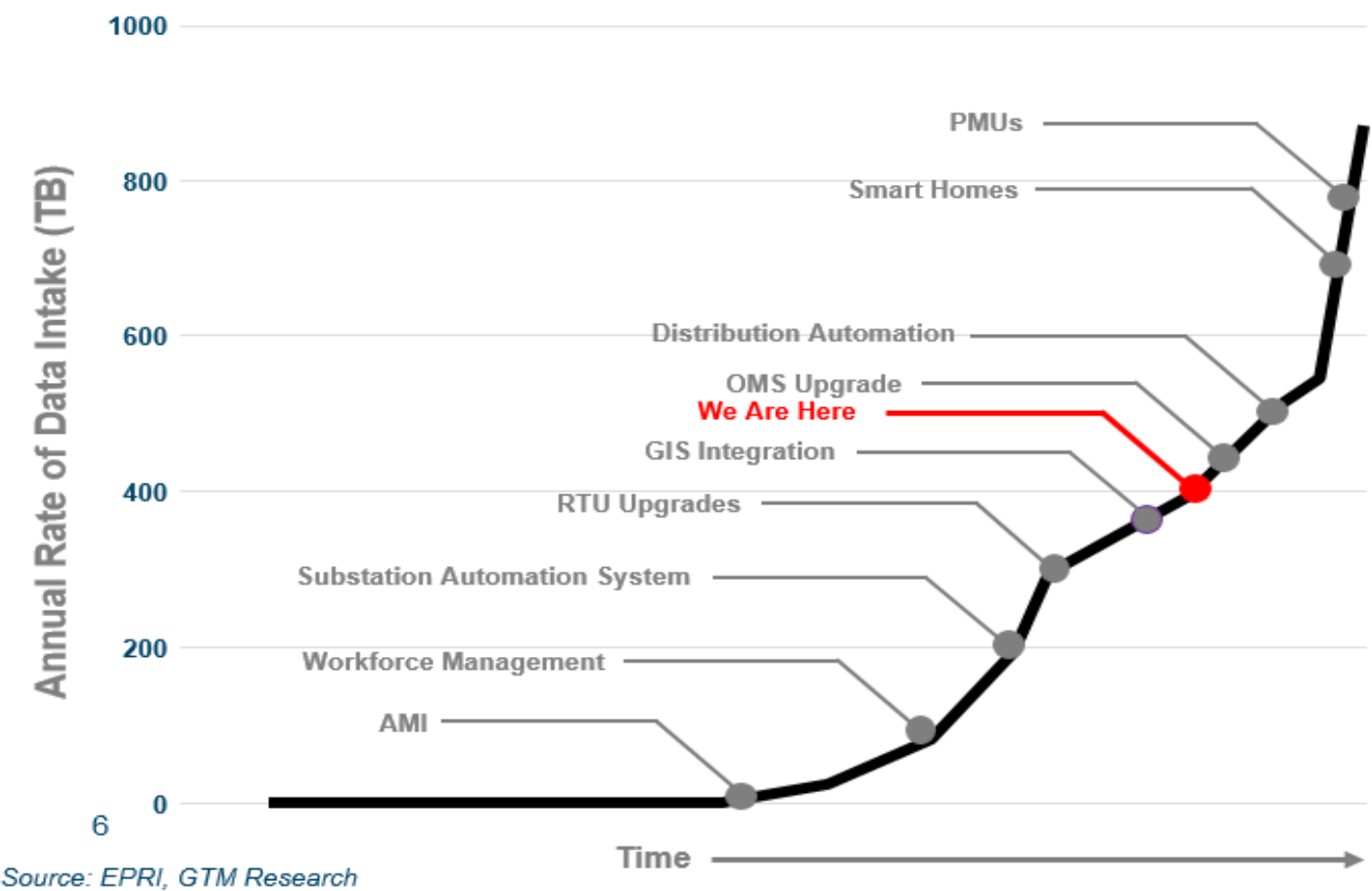

Figure 4: Exponential data growth for utilities organization

\subsection{Transformation towards Autonomous Markets}

In many countries grid business is regulated non-competitive segment due to its inherent nature. Regulators are playing major role in perceiving policies, tariff structure. Study reveals that in order to achieve the goals of autonomous markets, focus 
of Governments and their regulatory bodies have been to identify, establish new services, and business models in order to sustain or improve their revenues and to bring in more system and operational efficiency. This involves stage-managing of their people, legal \& regulatory framework, organization \& social behaviors and inclusion of appropriate technologies and solutions towards achievement of their autonomous market objectives. The Table 1 represents high level challenges or factors under three broad categories such as people, framework and technology. In the following sections various influences such as shrinking grid businesses, ageing infrastructure \& increasing regulatory pressures, etc., are explained. Specific focus have been given on grid organizations with the emphasis to prevent them from death spiral due to shrinking grid businesses.

Table 1: Challenges for establishment of competitive electricity markets

\begin{tabular}{|l|l|l|}
\hline People & $\begin{array}{l}\text { Organization, regulatory \& Legal } \\
\text { framework }\end{array}$ & $\begin{array}{l}\text { Infrastructure \& } \\
\text { Technology }\end{array}$ \\
\hline Awareness & Government Policies and Legal & Energy System \\
Consumer & Framework & Infrastructure \\
Interest & Organizational design & Operation Technology \\
Supplier & Influences \& Benefits & Information Technology to \\
Motivation & Threats & manage \\
Skills \& & Advertisement \& Promotion & a) Markets \\
Training & & b) Asset \& Grid \\
& & c) Customer \\
\hline
\end{tabular}

\subsubsection{Shrinking Grid Business}

Review of the influences discussed in the above sections reveals that due to increased dependence of renewables and energy storages, prosumers or consumers have falling dependency on grid and thus energy transferred through the grid are likely to shrink. Due to diminishing nature of energy transferred through the grid utilities expects strong shift in price ratios towards providing reliable backup power source or towards high availability for ensuring selling of excess energy to the grid. This means expectations of consumers on grid companies is likely to increase and metrics based (for example, availability based) open access pricing is foreseeable in future. It would require analyzing grid availability or power quality at more frequent intervals and applying dynamic metrics based tariffs than practiced now. Also the tough regulatory pressures along with trend of journey towards zero energy structures and micro grids would soar larger challenge to sustain grid companies' business.

\subsubsection{Ageing Infrastructure \& increasing regulatory pressures}

Utilities struggle to cope up with huge reduction in regulated revenues while there is a huge investments allocated towards renewables. Also with cost reduction as major objective, regulators enforce grid operators to identify other opportunities for bringing down capital investments and operational expenditures (CAPEX \& OPEX). In addition 
to this utilities are also pushed towards investing on renewable. This means existing preventive maintenance practices will not scale up and hence utilities need to look for practices like deferred network augmentation and however are compelled to maintain existing service levels. It becomes imperative for utilities to apply advanced asset performance innovations to establish stringent year-on-year cost reduction targets.

\subsubsection{Ageing and diminishing skilled manpower}

The Figure 5 depicts Center for Energy Development's Survey ${ }^{7}$ results. It clearly indicates that rate at which highly skilled resources will diminish is high, which means as a whole, almost $55 \%$ of the workforce may need to be replaced in the next 10 years. And it is imperative that utilities need to engage and act faster to meet this challenge to avoid knowledge attrition. For illustration survey in Japan suggests that as of 2013 a quarter of the nation's population was age 65 or older $^{7}$. This demographic ${ }^{8}$ is projected to expand to 36 percent by 2040 , and will reach 40 percent by 2060 . This means government and or regulators needs to plan to tackle this critical scenario to maintain metrics such as grid reliability, system \& operational efficiency, safety etc.

\begin{tabular}{|c|c|c|c|c|}
\hline & $\begin{array}{r}\text { Potential } \\
201\end{array}$ & $\begin{array}{l}\text { Replacements } \\
13 \text { - } 2017\end{array}$ & $\begin{array}{r}\text { Potentia } \\
20\end{array}$ & $\begin{array}{l}\text { Replacements } \\
18 \text { - } 2022\end{array}$ \\
\hline Job Category & $\begin{array}{c}\text { Potential } \\
\text { Attrition \& } \\
\text { Retirement }\end{array}$ & $\begin{array}{l}\text { Estimated Number } \\
\text { of Replacements }\end{array}$ & $\begin{array}{c}\text { Potential } \\
\text { Retirement }\end{array}$ & $\begin{array}{l}\text { Estimated Number of } \\
\text { Replacements }\end{array}$ \\
\hline Lineworkers & $32 \%$ & 24,100 & $14 \%$ & 10,300 \\
\hline Technicians & $41 \%$ & 28,300 & $14 \%$ & 10,100 \\
\hline Plant Operators & $42 \%$ & 14,900 & $13 \%$ & 4,600 \\
\hline Engineers & $34 \%$ & 9,200 & $12 \%$ & 2,900 \\
\hline Total & $36 \%$ & 76,500 & $14 \%$ & 27,900 \\
\hline
\end{tabular}

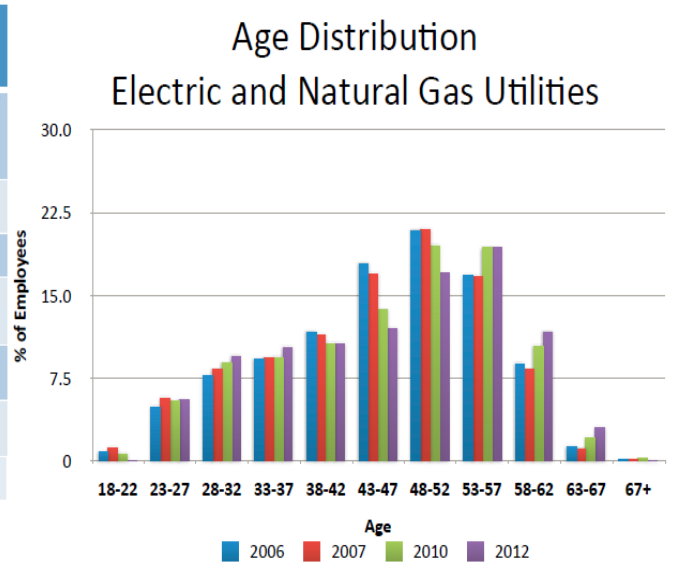

Figure 5: Diminishing Skilled manpower

\subsubsection{Enablers of competitive environment}

It should be noted that the transformation could only be possible subsequent to empowerment of each stakeholders with an appropriate information that will help them make informed decisions to perform their business with economy as prime focus. Thus government has key imperative to ensure that none of the stakeholders are vulnerable to economic unviability prior to unbundling due to unavailability of competitive environment especially lack of governed timely \& right perspective information. This transformation involves series of actions by utilities under various domain such as people, legal \& regulatory framework, social \& organization behavior and technology are picked up to achieve the required maturity ${ }^{9}$. In this paper specific focus has been given related to few key technologies to empower stakeholders with digital experience in the following sections. 


\section{RESULTS AND DISCUSSION}

\section{Enablement through Advanced Analytics \& Cognitive Solutions}

In this section how each utility stakeholder across globe are progressing to attain their target goals through the use of advanced analytics and cognitive solutions powered by infrastructure solutions such as Cloud, Internet of Things and mobile are discussed ${ }^{10}$. The Figure 6 depicts a functional overview of utilities solutions to enable various stakeholders such as generation, grid, customers, retailers, energy service, renewable providers, market exchanges etc. In this summary, key solutions under the category of advanced analytics and cognitive solutions with a use case example are discussed and it does not represent entire solution portfolio due to limitation of the current scope. Technology factors were studied with focus on factors such as Data Explosion, Diminishing Expertise, Disruptive Innovation, Digital experience, societal inclusion and Economic sustenance. It is evident that both advanced analytics and cognitive solutions are complement to each other and are becoming business imperatives. The requisite and nature of solutions are explained in below section with at least one specific use case of each solutions. It is intended to elaborate on each solutions, benefits and their integration with other business as usual applications in different publications in future.

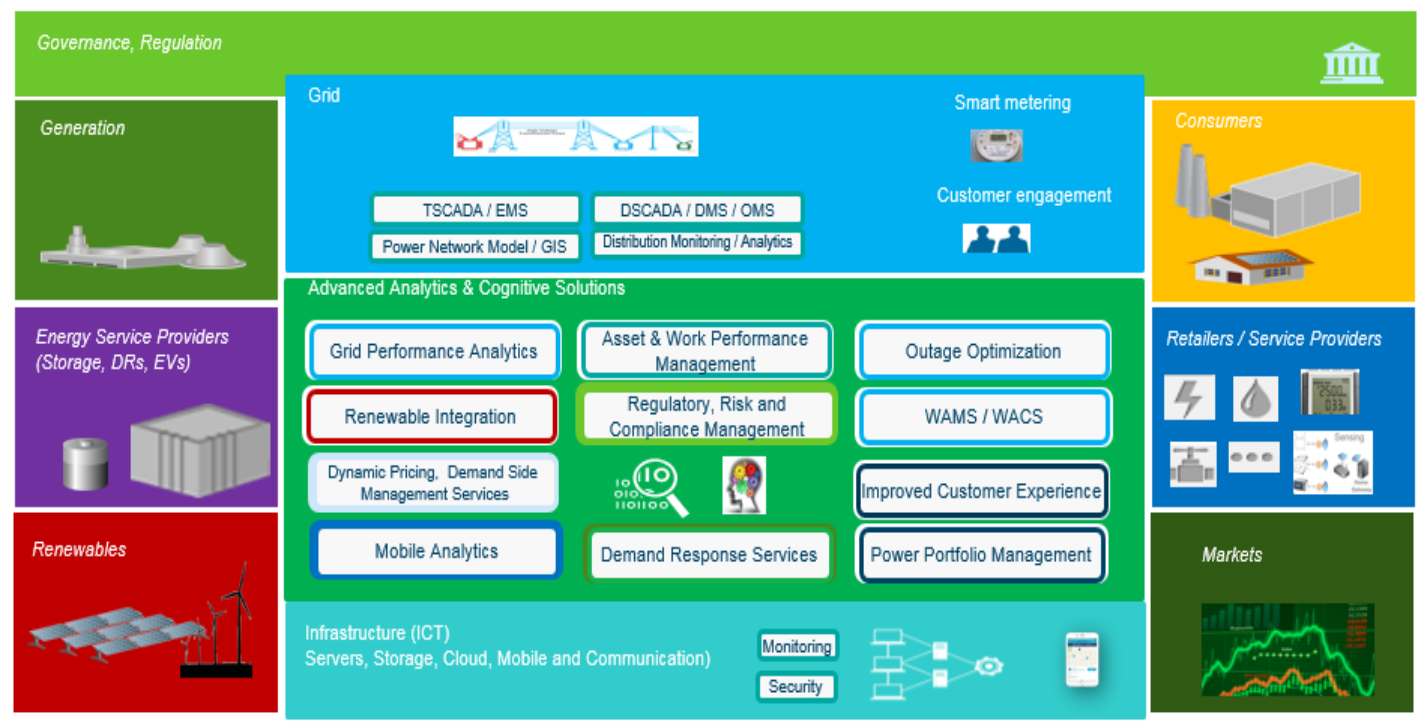

Figure 6: Portfolio of Solutions for various electricity market stakeholders

\section{Advanced Analytics}

Worldwide due to varying business models, for many grid utilities complexity increases while managing their ageing infrastructure, diminishing skilled resources, they also have additional responsibility for managing their own distributed energy resources, provide an ability for market operations to perform with more efficiency and economy. Hence it is vital that the grid companies' system architectures must be equipped to play a challenging role of energy and system integrators. Traditionally utilities are cautious 
adopters of technologies due to its inherent regulatory and public apprehensions. However most of global utilities are in the midst of smart grid or digital transformation. As business models evolving - some are privatized, many of vertically integrated utilities have started unbundling, now new franchisee models pop up, multiple suppliers in same region especially in metros, open access is on for large customers and being targeted for small scale consumers in the future. Customers are more engaging than ever before in utilities business and holds high expectations than those are currently realized.

All these challenges combined with market forces are compelling executives to think beyond the traditional approaches and embrace the new technologies. Thus thoughtful application of each solutions in an innovative way is essential. Also convergence of Information \& Operation technologies (IT \& OT) (example, smart meters sending power quality \& consumption data every 10-15 minutes increases volume by of meter read by approximately 2800 times compared to once a month read) which are causing exponential data growth. Although various sources are contributing to growth, it is essential to empower stakeholders leveraging of type and other attributes of data ${ }^{11}$. Typical example of benefit areas for grid companies include a) Predict Asset performance and defer network investments b) increase operational efficiency c) Optimize Outage restoration d) Power portfolio optimization etc. It is important to note that new challenges being spanned due to additional analytics deployments. Here it is not just volume, but velocity \& variety of the data are also increasing. As we discussed earlier, these new opportunities ${ }^{12}$ should address the challenges caused by the three famous ' $V$ ' of big data being experienced by utility.

Volume: Smart meters, PMUs, sensors, integration with Supervisory Control And Data Acquisition (SCADA), Energy Management Solutions (EMS) and Distribution Management Solutions (DMS), are generating new data in a volume that utility staff or systems were not designed to handle

Velocity: Time scale of data arriving ranges from few milliseconds from PMUs and Advanced Metering Infrastructure (AMI) interval data to all the way to once a month from customer payment and all time intervals in between.

Variety: Sources of data ranges from utilities internal \& trusted sources to blogs from customers, format of data can be a well-defined structure or free unstructured format text.

Use case from various grid companies' represents predicting peak load which involves high complex customer energy models, segmentation models, demand forecasting based on various other parameters such as weather, cloud etc., and help optimize dispatch through demand response solutions. 


\section{Cognitive Solutions}

Cognitive solutions uses natural language processing and machine learning to reveal insights from large amounts of unstructured data. Typically for utility industry unstructured data set includes manuals and user guides, thermal images, videos, operational or transactional notes, social \& weather interactions etc. A cognitive solution helps to observe, interpret, evaluate and make informed decisions. It self learns knowledge, converts into hypothesis and further facilitate stakeholders or employees to perform better. Through the study of effects of ageing workforce and data growth as explained above sections, it is evident that there is a need for a set of solutions with self-learning capabilities and as well could capture the human and machine (both structured and unstructured) knowledge through capabilities such as natural language processing, and help apply statistical \& network analysis. It should also facilitate information exploration capabilities such as hypothesis generation and evidence expression. The Figure 7 explains the approach to encounter increasing customer expectation with ageing work force and increasing data ${ }^{13}$. It suggests that upgrading or speed up the time to resolve per each workers is essential. This means implementation of cognitive solutions could help through knowledge capture, retention and reapply into analytics to provide insights for the newly skilled or unskilled resources. It is intended to discuss detailed use cases in next publications including the topics such as microgrid $^{14}$, WAMS/WACS including setting less protections, etc.,

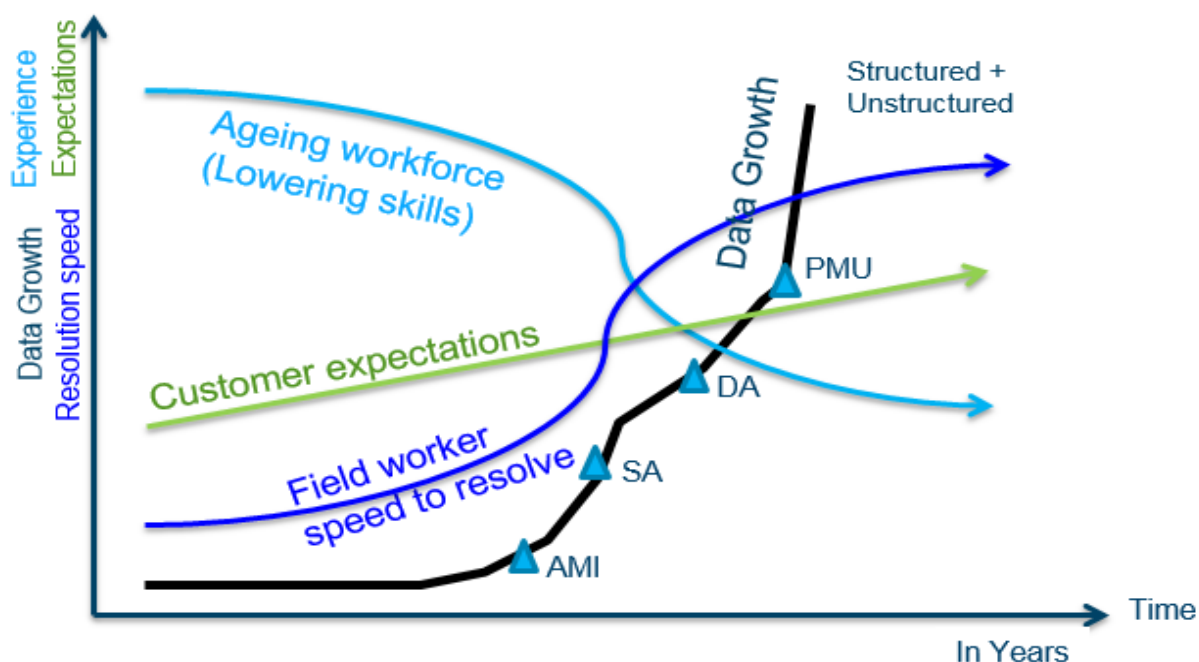

Figure 7: Chart which represent the approach to Improve speed to resolve of field workers through cognitive solutions

\section{CONCLUSION}

Study of global utilities stakeholders suggests that for realization of autonomous market maturity requires coherence of appropriate strategy \& roadmap followed by step by step implementation of various solutions which includes not just technology applications but also various initiatives to align their people, legal \& regulatory framework, social 
\& organizational behavior. It was envisaged to lever this publication by emphasizing on key facets of those technologies and present some of use case areas. The study enlightens that the advanced analytics and cognitive solutions play key role towards competitive objectives. It also indicates that data is key for bringing insights for key decision making, three key requirements such as volume, variety and velocity needs to be accounted while designing analytics platform. The requisite solution shall not limit the ability to handle structured and unstructured data, it should also cater an ability to support cognition within and outside organization in order to manage lowering skills and customer expectations better.

This paper did not discuss other enabling technologies such as internet of things (IOT), cloud, social and mobile to enable utility organization to perform better towards competitive journey. The point of view to empower every stakeholder with digital experience to manage challenges from people, framework and technology have not been covered in this publication. One should always focus on extracting maximum benefits from any targeted technology investments includes advanced analytics, cognitive solutions powered by cloud, IOT and mobile capabilities. It is proposed to discuss every challenges and do deep dive into design of utility system architecture and also to provide insight on data governance and management methods which would play vital role in shaping the utilities analytics and cognitive journey in future.

\section{REFERENCES}

[1] The Smart Alternative: Securing and Strengthening Our Nation's Vulnerable Electric Grid Published on June 2008 by Kenneth R. Nahigian. http://www.reforminstitute.org/uploads/publications/Smart_Grid_Final.pdf. Date Accessed: 24/10/2015.

[2] https://www.iea.org/media/workshops/2015/esapplenaryjuly2015/Yamazaki.pdf. Date Accessed: 24/04/2016.

[3] Growth of Photovoltaics. https://en.wikipedia.org/wiki/Growth_of_photo voltaics. Date accessed 29/04/2016.

[4] Wikipedia-Grid Parity. https://en.wikipedia.org/wiki/Grid_parity. Date accessed 29/04/2016.

[5] E.ON History Profile. http://www.eon.com/en/about-us/profile/history.html. Date accessed 29/04/2016.

[6] Blog by Luke Osborne on Jan 2016. http://www.repositpower.com/theblog/fourthings-household-batteries-can-do. Date accessed 29/04/2016.

[7] Gaps in the Energy Workforce Pipeline 2013 Survey Results. http://www.cewd.org/Documents/2013CEWDSurveyExecutiveSummary.pdf.

Date accessed 29/04/2016.

[8] Tokyo drift: How Japan can turn its aging workforce into an advantage by Jonathan Woetzel, Michael Chui, and Georges Desvaux. http://www.mckinsey.com/mgi/overview/in-the-news/tokyo-drift. Date Accessed: 29/04/2016. 
[9] Smart 2020: Enabling the low carbon economy in the information age. http://www.theclimategroup.org/assets/resources/publications/Smart2020Report .pdf. Date Accessed 28/03/ 2016

[10] IBM Institute of Business Value Analytics research, Massachusetts Institute of Technology. The New Intelligent Enterprise. IBM, MIT Sloan Management, United States, 2011

[11] IBM Center for Applied Insights study, Economist Intellige2011nce Unit, IBM Institute of Business Value. Outperforming in a data-rich, hyper-connected world. IBM: New York, 2012

[12] IDC, State of the U.S. Business Analytics Software Market: End-User Perspective by Vertical Industry and Company Size. IDC Corporate Headquarters: 5 Speen Street, Framingham, MA 01701, June 2011

[13] Jayaprakash Ponraj, Glen Garner. The requirements and an approach to build cognitive utility. IBM Global Business Services: Tokyo, 2016.

[14] R. Effatnejad, H. Afshari and M. Savaghebi. Modeling and Simulation of Hybrid System in DC Micro-Grid Based on Photovoltaic and Energy Storage. Indian Journal of Science and Technology, 2015, 8(16), pp.1-8. 
